\title{
Cosmonauts and Lead: Resorption and Increased Blood Lead Levels during Long Term Space Flight
}

\section{Dear Editor,}

I examined previously reported facts obtained from space flights that may confirm that blood lead level substantially increases during long-term space flight. The increase is due to bone resorption (demineralization) and lead release from the bones and into the blood [1]. Since lead exposure has not been previously considered a problem in manned space programs, there are few experimental facts linked to this possible endogenous hazard. Nevertheless, in 1984, one interesting paper explored several serum enzymes in cosmonauts during five long duration missions on the Salyut-6 Space Station [2]. They measured enzyme activity just before the flight, one day after return $(\mathrm{R}+1)$, and 1-5 weeks after return. Except for reduction of activity in NAD-dependent malate dehydrogenase (MDH), Popova et al. explained the changes in enzyme activities. The authors noted that reduction of MDH activity was observed only after long-term space expeditions. For spaceflights that lasts from 72 to 185 days, the data provided in this article shows that activity of NAD dependent $\mathrm{MDH}$ is about $1 / 3$ lower on average when compared to initial pre-flight activity. Grigoriev et al. also noted this experimental result [3].

Reduction of $\mathrm{MDH}$ activity with lead exposure has been documented [4]. Although other common toxic metals such as mercury, cadmium or aluminum may also be sources of toxicity onboard the Space Station, there are no indications in the literature that these other toxic agents affect MDH activity as does lead. Thus, I suggest that reduction of MDH activity noted in cosmonauts is caused by lead released as a result of the welldescribed bone resorption process noted during spaceflights.

Assuming that NAD dependent MDH activity is dependent on chronic lead exposure due to bone resorption in microgravity, one may estimate average blood lead concentrations in cosmonauts upon landing. However, to estimate, one needs specific information. The comprehensive review of lead exposure biomarkers was found in Sakai [5]. It shows that one of the best biomarkers of lead exposure is nicotinamide adenine dinucleotide (NAD) synthetase (NADS) activity, which linearly decreases above threshold. Depending on the analytical methods described in the paper, the evaluated threshold value is between 5 and $10 \mu \mathrm{g} / \mathrm{dl}$ of blood lead (Pb-B) concentration. The $\mathrm{Pb}-\mathrm{B}$ level inducing 50\% inhibition of NADS activity is calculated to be $43 \mu \mathrm{g} / \mathrm{dl}$ of $\mathrm{Pb}-\mathrm{B}$. Let us note that MDH catalyzes the following reaction.

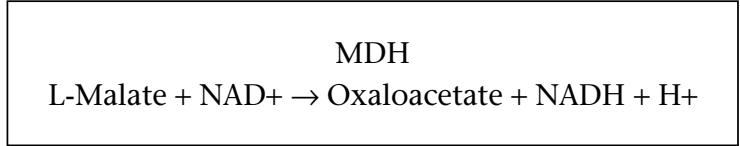

In addition, assuming that lead affects directly or indirectly all enzymes activities involved into the Krebs cycle in the same proportion, one may conclude that lead exposure causes NAD-dependent MDH activity proportional to NADS activity.

Therefore, average blood lead concentration $\mathrm{C}(\mathrm{Pb}-\mathrm{B})$ of cosmonauts upon return to Earth based on reported data may be estimated as $\mathrm{C}(\mathrm{Pb}-\mathrm{B})=43 * 0.33 / 0.5=28 \mu \mathrm{g} / \mathrm{dl}$, where 0.33 is reduction of serum NAD-MDH activity in Salyut- $6 \mathrm{R}+1$ post-flight measurements and 0.5 is the documented reduction of serum NADS activity with blood lead concentration of $43 \mu \mathrm{g} / \mathrm{dl}[5]$.

Based on the threshold data and the fact that, in the 1980s, the average blood lead concentrations in industrialized countries and the USSR was about $10 \mu \mathrm{g} / \mathrm{dl}$, we may conclude that pre-flight blood lead concentration in cosmonauts was 5-10 $\mu \mathrm{g} / \mathrm{dl}[6,7]$.

These data obtained from enzyme activities are in agreement with calculations based on our bone resorption lead kinetics hypothesis and represent the range of well-established toxic effects [1]. For comparison, with an initial blood lead concentration of $5 \mu \mathrm{g} / \mathrm{dl}$ and bone lead concentration of $20 \mu \mathrm{g} / \mathrm{g}$ after 100 days of spaceflight, our kinetic model gives blood lead concentration in cosmonauts at approximately $25 \mu \mathrm{g} / \mathrm{dl}$ of blood lead.

I wish to stress that the $28 \mu \mathrm{g} / \mathrm{dl}$ blood lead at the end of the Salyut- 6 missions is the estimated average value. Since the data shown in Popova et al. pertained in part to relatively short flights (72 days), the NAD-activity lead hypothesis suggests that the actual blood lead concentration after 180 days might be even higher [2]. It should also be noted that bone loss countermeasures were in effect during the Salyut-6 missions.

The evidence of spaceflight effects on NAD activity and the responsiveness of NAD activity to lead exposure, combined with the hypothesis that bone resorption during spaceflight will release lead stored in bones into blood circulation, warrants the monitoring of blood lead before, during, and after extended space missions. Vladislav S. Kondrashov, Senior Scientist, PhD 
Vladislav S. Kondrashov, PhD

Science Applications International Corporation

(SAIC)-Exploranium

6108 Edwards Blvd, Mississauga, Ontario L5T 2V7, Canada.

E-mail:vladislavs.kondrasovs@saic.com

\section{REFERENCES}

1. Kondrashov V, Rothenberg SJ, Chettle D and Zerwekh J, Evaluation of potentially significant increasing lead in the blood during long-term bed rest and space flight. Physiol. Meas.

2005;26(1): 1-12.

2. Popova IA, Vetrova EG, Drozdova TE Serum enzyme activity after long-term space flight, Kosm Biol Aviakosm Med

1984; 18(5):81-2 (in Russian)
3. Grigoriev AI et al. Main medical results of extended flights on space station Mir in 1986-1990, Acta Astronautica 1993;29, 8, pp. 581-585.

4. Jarrar BM and Mahmud ZN. Histochemical Demonstration of the Alteration in the Renal Dehydrodenases Activity Induced by Lead in Wistar Albino Rats (Rattus Norvegicus), Journal of Health Science. 2002;48(2), 106-117.

5. Sakai T. Biomarkers of Lead Exposure, Industrial Health. 2000; $38,127-142$.

6. CDC. Annual summary 1980: reported morbidity and mortality in the United States. MMWR. 1981;29(54)

7. Skalny AV, Kislyuk GI, Jatsik GV, Skalnaya MG The concentration of macro- and trace elements in feto-placental system and the clinical prognosis in children. Proceedings of 7th European Nutrition Conference, May 24-28, 1995, Vienna, Hofburg, p.76. 